\title{
Promoting positive perceptions and person centred care toward people with mental health problems using co-design with nursing students
}

\author{
Stephen Tee ${ }^{\mathrm{a}, *}$, Yeter Sinem Üzar Özçetin ${ }^{\mathrm{b}}$ \\ a Bournemouth University, Faculty of Health and Social Sciences, Royal London House, Christchurch Road, Bournemouth, UK \\ ${ }^{\mathrm{b}}$ Hacettepe University Faculty of Nursing Psychiatric Nursing Department, Hacettepe University Faculty of Nursing, Psychiatry Nursing Department, 06100 Sihhiye-Ankara, Turkey
}

\section{A R T I C L E I N F O}

\section{Article history:}

Received 18 January 2016

Received in revised form 15 May 2016

Accepted 24 May 2016

\section{Keywords:}

Mental health

Co-design

Person-centred care

Education

\begin{abstract}
A B S T R A C T
Background: People experiencing severe mental health problems often feel excluded from society due to stigmatization and prejudice. They typically experience negativity and lack life opportunities, which can be reinforced by the attitudes of those around them.

Health care professionals, especially nurses, have the opportunity to challenge negative perceptions through role-modelling hope and positive expectation, breaking down barriers to participation and challenging discrimination. However, student nurses can enter the profession with attitudes similar to those of wider society and unless addressed can foster life-limiting approaches toward those for whom they are providing care.

Aim: This study aimed to design a person-centred education approach in response to an evaluation of the attitudes of nursing students in Turkey toward people with mental health problems.

Method: A qualitative design adopting descriptive phenomenology. Data were collected from 12 undergraduate nursing students by using in-depth semi-structured interviews. Data were transcribed and themes identified which were used to co-design a person-centred education approach.

Results: Three themes emerged from the data; (1) meanings attributed to mental illness, (2) moving from fear to understanding, (3) promoting hope and positive change Students typically demonstrated perceptions/attitudes that could be inhibiting to future practice.

Conclusions: The pedagogy employed in this study moved away from a focus on signs and symptoms of illness to person-centred approaches. More positive perceptions of mental health can be developed through codesigned, person-centred educational approaches.
\end{abstract}

(c) 2016 Elsevier Ltd. All rights reserved.

\section{Introduction}

Mental health problems, such as psychoses, can cause serious and disabling changes to a person's thoughts, emotions, perceptions and behaviour (WHO, 2016). Treatment may require long-term intervention from mental health services including periods of hospitalisation. But modern treatments and psychosocial approaches have improved recovery rates resulting in a much more positive outlook for those experiencing mental illness. However, it is not only mental illness that causes problem. Individuals can experience stigma and discrimination resulting in reduced access to health and social services and, according

\footnotetext{
* Corresponding author at: Faculty of Health and Social Sciences, Bournemouth University, Royal London House, Christchurch Road, Bournemouth BH1 3LT, UK.

E-mail addresses: stee@bournemouth.ac.uk (S. Tee), sinem_uzar@hacettepe.edu.tr (Y.S. Üzar Özçetin).

URL: http://www.bournemouth.ac.uk (S. Tee).
}

to the World Health Organisation (WHO, 2013a, 2013b, 2016) a significant risk of violation of human rights.

The consequence of such negative societal attitudes can be social solation, life limiting choices and delay in help-seeking behaviour (Schulze and Angermeyer, 2003; Yanos et al., 2010; WHO, 2016). Nurses have a significant role in mental health care delivery and need to be aware of their personal impact in providing high-quality mental health care and promoting positive images of mental health. However the preparation of student nurses in issues of mental health can be challenging, given prior personal experiences and assumptions (Heyman et al., 2015). This is particularly the case when the time devoted to mental health issues in a generic training programme is limited. It is therefore incumbent on educators to find impactful ways of preparing student nurses in mental health that explore such prior assumptions and develop insights that foster positive attitudes.

Given the importance and sensitivity of perceptions of mental health in the preparation of students undertaking a generic nurse training, this study sought to develop a more tailored package of education. The 
purpose was to co-design education based on the attitudes and feedback of a cohort of nursing students in order to identify personalized education strategies that would enable students to develop their understanding, empathy and intervention using a person-centred care framework to promote hope and recovery.

To illustrate the nature of person-centred care, National Voices (2013), a movement formed from several UK charities suggest PersonCentred Care is simply a process that means:

"I can plan my care with people who work together to understand me and my carer(s), allow me control, and bring together services to achieve the outcomes important to me."

\section{Background}

\subsection{Stigma and Dehumanization}

Understanding society's attitudes towards mental health and mental illness is essential for helping educators ameliorate negative behaviours and responses in healthcare students (Loch et al., 2013). Changing negative attitudes is challenging because people are presented with negative stereotypes through the media, about mental illness, despite significant advances in treatment and outcomes (Omori et al., 2012). Stigma arises from the negative attitudes, beliefs and behaviours of others and can have a significant effect on individual wellbeing (Charles, 2013). Stigma can lead to dehumanization especially amongst people suffering from mental illness and the process can deprive individuals of human qualities, personality and spirit (Charles, 2013; Kwan and Fiske, 2008).

\subsection{Providing Effective Inter-Personal Care}

Health care professionals, like any other member of society, can be a force for positive change in the community in which they practice (Sartorius, 2002). However the opposite can be true where health professionals mirror the negative, exclusionary and stigmatising behaviours of the wider society (Feret et al., 2011; Ross and Goldner, 2009). The nature of health care involves helping people integrate within society, particularly those who are vulnerable and in need of support. Understanding the power vested in inter-personal relations is important for maintaining positive therapeutic relationships to avoid dehumanization and causing the individual to feel stigmatised (Tee, 2016).

Through effective experiential and clinical theory based education, student nurses can become aware of these important interpersonal processes in order to bring about attitudes that improve outcomes (Heyman et al., 2015). One of the key principles is the adoption of person-centred care.

\subsection{Person-Centred Care}

Person-centred care (PCC) can be defined as an equal partnership between the nurse and person receiving care or their family. In longterm care it focuses on providing holistic care to people to improve quality of life, enhance wellbeing and autonomy (Williams et al., 2015). It contrasts with a task-oriented, dehumanized approach but embraces individual humanity (Tee, 2016). Experiencing ourselves as human is essential to building effective interpersonal relationships (Bastian and Haslam, 2011). PCC is an attitude that helps release change and growth in the personality and behaviour and helps individuals to have the freedom to choose (Tee, 2016).

Whilst there is extensive literature highlighting some of the organisational and cultural challenges to implementing PCC in practice, national and international governing and policy bodies such as the WHO (2013a, 2013b, 2015), continue to advocate PCC as the philosophy and framework for high quality care and this extends to the essential qualities and skills of the nurse in practice. Linked to PCC is the person-centred nursing ( $\mathrm{PCN}$ ) framework, developed by McCormack and McCance (2010), which focuses on the attributes of nurses to deliver PCC. This includes interpersonal skills and self-awareness but also an awareness of patients' rights and expectations (Bolster and Manias, 2010). To develop such an approach the mechanisms of internalisation and reflection are key to transferring knowledge into action and establishing change (Larsson and Blomqvist, 2014). Therefore understanding the dynamics of power and control, authenticity, effective relationships and shared values are essential, the absence of which can create barriers to PCC (McCormack and McCance, 2010).

In the context of education traditional didactic education approaches that centre on signs and symptoms and management may fail to address the deeper core beliefs of students, whereas the nature of a person-centred pedagogy means bringing assumptions, attitudes and perceptions to the fore so that they can be explored and modified in the face of evidence bringing about new insights. So by working with beliefs and values, engagement skills and, shared decisionmaking, learners can be encouraged to identify opportunities for increasing service user participation (Bolster and Manias, 2010) and internalising the values of PCC. The education design and delivery process therefore has great significance for the development of professional practice.

\subsection{Context of the Study}

This study was conducted in Turkey where nursing students graduate as a general nurse after a 4-year programme at University. After receiving their BSc, they can specialise by undertaking an MSc and/or PhD. The mental health/psychiatric nursing component is provided in the final $4^{\text {th }}$ year although some may undertake elective lessons focused on mental health and illness before the final year of their education.

Turkish nursing students typically study mental health/psychiatric nursing through a didactic and theoretical model with limited time for more experiential learning. After receiving their theoretical education they undertake clinical placements in psychiatric units and general wards as part of 'Consultation-Liaison Psychiatry'. Consequently, nursing students who do not specialise in mental health at a postgraduate level have very limited insight into mental health issues. These limitations can be a barrier to internalising positive perceptions and so the education provided needs to be as impactful as possible, over a short period of time, in order to develop the desired humanistic, personcentred values and behaviour. The person-centred approach adopted in this study is consistent with the aims outlined in a joint World Health Organisation (WHO) and Government of Turkey Conference in 2013 focused on transforming mental health care (WHO, 2013a, 2013b).

\section{The study}

This study aimed to co-design a person-centred education approach in response to an evaluation of the prior experiences and attitudes of nursing students in Turkey toward people with mental health problems. A three-stage process was employed:

1. Semi-structured interviews amongst a cohort of nursing students to determine baseline understanding, attitudes and beliefs

2. Thematic analysis to determine educational focus of the mental health training

3. Co-design of a tailored training programme

\subsection{Ethical Considerations}

This study was designed around the ethical principles of beneficence, autonomy, non-maleficence and justice. The necessary ethical approval was obtained from the Non-invasive Clinic Studies Ethical Board of Hacettepe University, Turkey. Throughout implementation, 
students were informed of the purpose of the study, that participation in the study was voluntary and that study results would be used only for the purpose of education design and future publication.

\section{Method}

The evaluation of the students' attitudes and beliefs was conducted using a qualitative design adopting a descriptive phenomenological approach. Descriptive phenomenology was used in this context to illuminate and understand students' prior experiences of, and encounters with, severe mental health problems. As Balls (2009) points out, phenomenology allows us to re-examine "taken-for-granted" experiences and then through analysis identify the core of that experience. The resulting data would then form the focus of a co-designed learning package with students.

The study aims were as follows:

1. To explore nursing students understanding of severe mental health problems.

2. To examine the attitudes/perceptions/beliefs nursing students hold toward people with severe mental health problems

3. To adopt a co-designed pedagogical approach to promote humanistic, person-centred care

\subsection{Sample}

This study was undertaken with a group of Turkish Nursing Students. In-depth interviews were held with 12 students, from a total cohort of 350 studying at a Faculty of Nursing. Participants were selected utilizing a purposive sampling method focusing on those students who had chosen to work in mental health. All voluntarily agreed to be involved in the study and received a verbal description of the study with the opportunity to ask questions about participation.

\subsection{Data Collection}

Audio-typed semi-structured interviews were conducted with the sample of nursing students undertaking mental health training as part of a nursing degree at a university in Turkey. Semi-structured interviews have the advantage of developing empathy, allowing flexibility and producing richer data than other methods (Simith, 2008). The interview comprised 8 open-ended questions, developed by researchers from the literature on mental health attitudes and perceptions. The questions explored understanding of terminology, beliefs and feelings about mental illness and sought suggestions on how they might best learn about supporting people with severe mental health problems.

Some socio-demographic questions were also included that sought information on age, gender, class of enrolment. The same questions were asked of all students and an audio recording of each interview took an average of 90 minutes each.

\subsection{Data analysis and identification of themes}

The audio-recorded data were transcribed, analysed and coded by the researchers. By reading each transcript multiple times, a comprehensive understanding of the data was achieved and coding could occur. Key themes began to emerge with sub-themes being developed by combining codes. There were three main themes. The researchers shared their interpretations with one another until they agreed on those that best represented the meanings of participants' statements.

\subsection{Education design phase}

The three overarching themes were then used to co-design a targeted education package that included experiential approaches to explore attitudes and beliefs, consider the evidence for mental health practice, the clinical skills of engagement and relationship building and exposure to practice experience.

\section{Results}

All students in the study were female; four were fourth year, four were third year and four were second year. All students were aged between 21-25. Eight had undertaken some very brief prior learning about mental health, whilst four had no prior learning on the topic. The student responses resulted in three overarching theme which were; (1) meanings attributed to mental illness, (2) moving from fear to understanding, (3) promoting hope and positive change.

\subsection{Meanings attributed to mental, health illness}

Whilst participants described the concept of 'mental health' in positive terms of maintaining one's daily life, independence and relationships with society thus:

"It means individuals' maintaining their work, in other words, their daily lives. Without being dependent on another"

They overwhelmingly attributed negative meanings to any mental illness diagnosis especially schizophrenia:

"Classically, the term lunatic. For example schizophrenia, what comes to my mind is a man with a neglected appearance, without a properly groomed look, making awful sounds, just the way they used to scare us when we were children."

Mental illness was associated with 'failure' to maintain one's daily life activities and a 'lack' of emotional and mental sufficiency. They suggested it resulted in a lack of mental ability, including intellectual ability:

"there is a failure of proper execution of abilities based on both physical degeneration in the brain and psychological trauma.

"the life of the individual is negatively affected. There is an inability to act like a normal person. They react abnormally."

The terms psychosis and schizophrenia were generally seen to have life-limiting connotations including feelings of isolation, aggression and terror:

“... they may not think of the consequences of their actions, including damage to and the death of others.

"They can attack, but they may not be aware of the consequences",

"All people with schizophrenia have mental weakness, but not all people with mental weakness have schizophrenia."

They saw dependence on other people as an inevitable consequence of mental health problems:

"These people should not be left unaccompanied because when they are alone, their aggression can increase and they can harm others, intentionally or unintentionally; “...., these people need supervision."

And this lessened their ability to make decision about their lives

"I believe they do not have enough ability, so they should not make decisions. I do not believe they are able to make the right decisions."

The assumptions displayed in just these few quotes were not untypical and clearly reflect a lack of understanding of modern concepts of 
mental health and the use of phrases such as "these people", are indicative of underlying attitudes that could inhibit therapeutic engagement.

\subsection{Moving from fear to understanding}

Many of the participants' beliefs about severe mental illness were often linked to societal influences such as stories in the media or portrayal in movies as well as prior contact with people who had mental health problems, such as those who were homeless. Many expressed fear of meeting or even seeing people with severe mental illness:

"I have a strong impulse to escape. I need to move away. I feel scared. If I have to be in the same room with these patients, I need to ensure that someone else is with me."

Where that person was family or a close friend, their viewpoint was more positive and accepting:

"I would not be able to accept it at first, maybe because it is a disease, but then I would think what to do, where to go, how to help."

If the person was known to the student, they expressed more optimism about the help available:

"I would do my best ... there certainly is a treatment, they need to take regular medication and receive psychological support; they need to be integrated into society. I would not isolate him/her."

However few expressed much hope about the treatments they had observed:

"It cannot be treated. What I saw was sedation with medication and suppression. I believe it cannot be treated...it takes a lifetime to recover."

"It is better for them to be at the hospital in advanced phases with attacks because immediate intervention and sedation are available."

Some suggested there was value of religious/traditional healers in the treatment of mental illness in addition to medical treatment:

"I think it is useful; it creates a positive effect...maybe the person can get rid of the disease with praying. I mean getting rid of those thoughts."

The responses illustrate where the focus of any educational intervention should sit in terms of helping the participants come to new understandings, develop empathy and tolerance and identify engagement and support strategies.

\subsection{Promoting hope and positive change}

It was evident that participants' experiences were predominantly negative suggesting the need for positive stories and outcomes in relation to severe mental illness to counteract perceptions. In particular they felt that interactions with people with mental illness should occur in the classroom as part of their training:

"Not everything can be learnt through theory; practice experience is necessary. Positive contact with the individual can affect your approach."

In fact from prior experience in other health contexts they found the telling of stories and learning from experience had the most influence on their learning. But added by developing a positive viewpoint would only be gained by exposure to positive experiences in practice:

"If we have a certain positive experience, we cannot continue with the same viewpoint as it challenges our and society's negative perception and leads to more positive practice."

\section{Discussion}

The attitudes and beliefs conveyed in this data are not untypical of those that may be found in a wider sample of the general population. As the UK Mental Health Foundation (2016) point out, people in society often have "stereotyped views" about mental illness and its impact on people. This often extends to the belief 'they' are violent and dangerous, when in fact self-harm is the bigger risk.

Mental health care in Turkey has been the focus of considerable attention recently with calls for new approaches and training of key staff. Mental health problems are not openly talked about in Turkey (Andrew, 2012) and there have been a number of initiatives such as a World Health Organisation sponsored conference, funded by the Turkish government in 2013, focused on transforming mental health care raising public awareness. Key to this transformation is the introduction of person-centred approaches to care planning.

The participants in this study were students on a generic nurse training who had limited exposure to mental health education, therefore any learning experience had to be as impactful as possible, in order to maximise the benefit for their future involvement in mental healthcare.

Whilst the transmission of facts about mental health has some value, there is good evidence to support the use of experiential over didactic learning methods in developing knowledge and insight into sensitive subject areas (Stiernborg et al., 2010). The purpose of this study was to engage students in a co-design process that would deepen their engagement with the topic, overcome their fears and apprehensions and support their development in the use of therapeutic engagement, shared decision-making and holistic care.

Working with the negative meanings attributed to people with mental illness means developing awareness of the consequences that such attitudes and behaviours can have in order to ameliorate their impact. The nursing students used dehumanizing language about people with mental illness labelling them as "schizophrenic", "mentally weak", "dependent" and "aggressive" and expressed reluctance to engage through fear and apprehension.

The co-designed education involves methods in which the students are more active in the process of learning. The first is the use of role-play simulation that has been shown to have beneficial impact particularly in mental health (Attoe et al., 2015; Fernando and Cross, 2015). Students can help design the simulation, drawing on their own experiences and acting out alternative responses and interventions. Added to this is the use of problem-based learning, which has been of significant benefit to students (Cooper and Carver, 2012) in promoting investigatory skills and questioning their assumptions about mental health. The co-design element involves students identifying the questions and searching the evidence to answer those they have set.

The involvement of services users is now recognised as a key element of any effective mental health education programme. This includes those with first-hand experience of mental health problems and of using mental health services as well as those who may be operating in a caring capacity. There is growing evidence for this approach in helping explore beliefs and assumptions and promoting positive images whilst developing insight and higher levels of empathy (Terry, 2013). The co-design aspect can involve students liaising with the service user organisations, identifying areas for discussion and leading conversations with groups of service users.

Student placements are also an essential component of the students' programme and can also involve significant elements of co-design. Allowing students choices that will enable them to fulfil a particular need or answer a clinical question can deepen their learning. Placements are important for students in achieving positive engagement, overcoming fear and establishing an emotional connection with people (Simpson, 2009). It is through this connection that students can practice shared decision-making, collaborate to access relevant information and enable person-centred selection of health care resources (Adams and Drake, 2006). Effective placement experiences also deepens 
understanding of holistic care as it requires nurses to engage the individual's wider social network and see beyond the diagnosis in order to overcome barriers to inclusion.

There is growing evidence for the benefit of co-design methods in education (Haraldseid et al., 2016) and indeed for improving services for users of healthcare (Donetto et al., 2014). Whilst more time consuming and resource intensive than other approaches, the most import outcome is the promotion of more positive practices amongst healthcare students that overcome the stigma and discrimination experienced by those with mental health problems.

\section{Conclusions}

Effective co-design and tailoring of education to meet the individual needs of students can be time consuming but is ultimately a worthwhile pursuit if it is to have the greatest impact on student learning and their clinical practice. Nursing students will often carry similar beliefs about mental illness to that of the wider society. Nurse education must aim to increase awareness and promote more positive insights in order to reduce the stigmatization and/or dehumanization toward sufferers.

A co-designed, student-centred pedagogy, in many ways mirrors a person-centred care philosophy, as it works with the individual values and attitudes to develop their personal insight and their ability to incorporate practical knowledge and awareness into clinical practice. This study reveals students may learn best when they can spend quality time with people who have lived experience of mental illness to deepen their understanding and challenge negative assumptions. Curriculum therefore needs to include effective protocols to facilitate involvement of people with mental illness in education and adopt experiential methods to compliment the theoretical education that can overcome fear/prejudices, promote positive attitudes, internalize knowledge and foster a person-centred approach to care.

In presenting these findings we recognize there are limitations to this work, including the relatively small sample of students from one university, located in Turkey, and that another larger sample conducted across a number of institutions might have revealed different results. However, we do believe that the results provide an important insight into the perception and attitudes of students' on a generic nurse training, toward mental illness and of the challenges of education codesign. As such this paper makes a useful contribution to those seeking to develop student-centred education that aims to reduce stigma and discrimination in our society.

\section{Acknowledgements}

The authors are grateful to all participants who agreed to participate voluntarily in this study.

\section{References}

Adams, J.R., Drake, R.E., 2006. Shared decision-making and evidence-based practice. Community Ment. Health J. 42 (1), 87-105.

Andrew, M., 2012. Attitudes Toward Mental Health. Turkey Central, Ankara (http://www. turkeycentral.com/topic/13980-attitudes-toward-mental-health/).

Attoe, C., Sherwali, S., Jabur, Z., 2015. Student interprofessional mental health simulation: Measuring the impact. BMJ Simul. Technol. Enhanc. Learn. 1 (Suppl. 2), A19-A20 (Accessed at: http://stel.bmj.com/content/1/Suppl_2/A19.3.abstract?sid= 51683447-74b1-4621-bf38-707c716bf906).

Balls, P., 2009. Phenomenology in nursing research: methodology, interviewing and transcribing. Nurs. Times 105 (32-33), 30-33.

Bastian, B., Haslam, N., 2011. Experiencing dehumanization: cognitive and emotional effects of everyday dehumanization. Basic Appl. Soc. Psychol. 33, 295-303.

Bolster, D., Manias, E., 2010. Person-centred interactions between nurses and patients during medication activities in an acute hospital setting: Qualitative observation and interview study. Int. J. Nurs. Stud. 47 (2), 154-165.
Charles, J.K.L., 2013. Mental health provider-based stigma: understanding the experience of clients and families. Soc. Work. Ment. Health 11 (4), 360-375.

Cooper, C., Carver, N., 2012. Problem based learning in mental health nursing : the students experience. Int. J. Ment. Health Nurs. 21 (2), 175-183.

Donetto, S., Tsianakas, V., Robert, G., 2014. Using Experience-based Co-design to improve the quality of healthcare: mapping where we are now and establishing future directions. King's College London, London.

Feret, H., Conway, L., Austin, J.C., 2011. Genetic counselors' attitudes towards individuals with schizophrenia: Desire for social distance and endorsement of stereotypes. Patient Educ. Couns. 82 (1), 69-73.

Fernando, A., Cross, S., 2015. Mental health simulation training: The bigger picture - why it's needed nationally. BMJ Simul. Technol. Enhanc. Learn. 1 (Suppl. 2), A23 (Accessed at: http://stel.bmj.com/content/1/Suppl_2/A23.2.abstract?sid=51683447-74b14621-bf38-707c716bf906).

Haraldseid, C., Friberg, F., Aase, K., 2016. How can students contribute? A qualitative study of active student involvement in development of technological learning material for clinical skills training. BMC Nurs. http://dx.doi.org/10.1186/s12912-016-0125-y.

Heyman, I., BJ, W., Tee, S., 2015. Curriculum development through understanding the student nurse experience of suicide intervention education-A phenomenographic study. Nurse Educ. Pract. 15 (6), 498-506. http://dx.doi.org/10.1016/j.nepr.2015.04.008 (2015 Nov, Epub 2015 May 9).

Kwan, V.S.Y., Fiske, S.T., 2008. Missing links in social cognition: the continuum from nonhuman agents to dehumanized humans. Soc. Cogn. 26 (2), 125-128.

Larsson, H., Blomqvist, K., 2014. From a diagnostic and particular approach to a personcentred approach: a development project. J. Clin. Nurs. 24, 465-474.

Loch, A.A., Hengartner, M.P., Guarniero, F.B., Lawson, F.L., Wang, Y.P., Gattaz, W.F., Rössler, W., 2013. The more information, the more negative stigma towards schizophrenia: Brazilian general population and psychiatrists compared. Psychiatry Res. 205 185-191.

McCormack, B., McCance, T., 2010. Person-centred Nursing: Theory and Practice. Wiley Blackwell, Oxford.

Mental Health Foundation, 2016. Stigma and Discrimination. (London, https://www. mentalhealth.org.uk/a-to-z/s/stigma-and-discrimination).

National Voices, 2013. A Narrative for Person-coordinated Care. National Voices, England https://www.england.nhs.uk/wp-content/uploads/2013/05/nv-narrative-cc.pdf.

Omori, A., Tateno, A., Ideno, T., Takahashi, H., Kawashima, Y., Takemura, K., Okuba, Y., 2012. Influence of contact with schizophrenia on implicit attitudes towards schizophrenia patients held by clinical residents. BMC Psychiatry 12, 205-213.

Ross, C.A., Goldner, E.M., 2009. Stigma, negative attitudes and discrimination towards mental illness within the nursing profession: A review of the literature. J. Psychiatr. Ment. Health Nurs. 16 (6), 558-567.

Sartorius, N., 2002. Iatrogenic stigma of mental illness. BMJ 324, 1470-1471.

Schulze, B., Angermeyer, M.C., 2003. Subjective experiences of stigma. A focus group study of schizophrenic patients, their relatives and mental health professionals. Soc. Sci. Med. 56, 299-312.

Simith, J.A., 2008. Qualitative Psychology: A Practical Guide to Research Methods. second ed. SAGE Publications, London.

Simpson, M.R., 2009. Engagement at work: a review of the literature. Int. J. Nurs. Stud. 46 1012-1024.

Stiernborg, M. Zaldivar, S.B., Santiago, E.G., 2010. Effect of didactic teaching and experiential learning on nursing students' AIDS-related knowledge and attitudes. AIDS Care 8 (5), 1996.

Tee, S., 2016. Person-centred Approaches in Healthcare. A handbook for Nurses and Midwives. McGraw Hill, London, UK.

Terry, J., 2013. The pursuit of excellence and innovation in service user involvement in nurse education programmes: Report from a travel scholarship. Nurse Educ. Pract. 13 (3), 202-206 (May 2013).

Williams, J., Hadjistavropoulos, T., Ghandehari, O.O., Yao, X., Lix, L., 2015. An evaluation of a person-centred care programme for long-term care facilities. Ageing Soc. 35, 457-488.

World Health Organisation, 2013a. Mental health action plan 2013 - 2020. World Health Organisation, Geneva, Switzerland (http://www.who.int/mental_health/ publications/action_plan/en/).

World Health Organisation, 2013b. Transforming Mental Health Care. "Promoting services for people with disabilities" Conference, Ankara, Turkey. Funded by the European Union (EU) and the Government of Turkey 2-3 October 2013 (http:// www.euro.who.int/en/countries/turkey/news/news/2013/10/transforming-mentalhealth-care-in-turkey).

World Health Organisation, 2015. WHO global strategy on people-centred and integrated health services. WHO, Geneva (http://www.who.int/servicedeliverysafety/areas/ people-centred-care/en/).

World Health Organisation, 2016. Mental health: strengthening our response. World Health Organisation, Geneva, Switzerland (http://www.who.int/mediacentre/ factsheets/fs220/en/).

Yanos, P.T., Lysaker, P.H., Roe, D., 2010. Internalized stigma as a barrier to improvement in vocational functioning among people with schizophrenia-spectrum disorders. Psychiatry Res. 178, 211-213. 